\title{
ССУДО-СБЕРЕГАТЕЛЬНАЯ МОДЕЛЬ ИПОТЕЧНОГО КРЕДИТОВАНИЯ: ОПЫТ ГЕРМАНИИ
}

\author{
(C) 2019 Понька Виктор Федорович \\ доктор юридических наук, профессор кафедры гражданского права, \\ процесса и международного частного права \\ Российский университет дружбы народов, Россия, Москва \\ E-mail:Vf_Ponka@mail.com
}

Статья посвящена рассмотрению опыта Германии в формировании правовых основ для развития различных форм накопительного ипотечного кредитования с использованием специализированных ссудо-сберегательных учреждений. Анализируются особенности и достоинства подхода, при котором этапы накопления первичного взноса вкладчиком и получение им ипотечного кредита опосредуются едиными договорными отношениями, отмечается важная роль государства в функционировании подобной системы.

Делается вывод о целесообразности заимствования накопленного в Германии опыта накопительного ипотечного кредитования в целях создания правовых основ для улучшения жилищных условий граждан Российской Федерации, повышение надежности и стабильности на рынке ипотечного кредитования и снижения ипотечной нагрузки на бюджеты российских семей.

Ключевые слова: ипотека, ипотечный кредит, ипотека Германии, рынок ипотечных услуг, процентные ставки

Развитие правового регулирования системы ипотечного кредитования в последние десятилетия основывалось на использовании унифицированных подходов, предполагающих участие в данной системе преимущественно кредитных организаций, деятельность которых не имеет специализированного характера.

Ипотека в российском законодательстве признается одной из форм залога недвижимого имущества, обеспечивающей гарантии исполнения финансовых обязательств, которые должник несет перед кредитором [7, С. 31]. Законодательство рассматривает как отдельные специфические подвиды ипотеку в силу закона и ипотеку в силу договора, а также устанавливает особенности правового регулирования ипотечных отношений для отдельных видов имущества или применительно к отдельным случаям возникновения, включая залог при передаче недвижимого имущества под условием выплаты ренты (ст. 587 ГК РФ), а также залог при государственной регистрации договора долевого участия (ст. 13 Федерального закона от 30.12.2004 № 214-Ф3 «Об участии в долевом строительстве многоквартирных домов и иных объектов недвижимости и о внесении изменений в некоторые законодательные акты Российской Федерации»).

При этом отечественное законодательство не уделяет достаточного внимания особенностям ипотечных правоотношений, обусловленных возможностью участия в них в качестве кредиторов различных видов специализированных организаций. В результате в Российской Федерации отсутствуют достаточные правовые основания для возникновения и развития таких специализированных кредитных ипотечных организаций и связанных с ними особых видов ипотечного кредитования.

Между тем зарубежный опыт, в частности, опыт Германии, свидетельствует о важности создания правовых условий для развития именно специализированных вариантов ипотечного кредитования, в том числе аналога действующей в Германии ссудо-сберегательной модели или «системы стройсбережений» [2, С. 21].

Традиционно признается, что в Германии действуют одни из самых низких в Европе процентных ставок по ипотеке [3, С. 48]. Это достигается за счет надежности предусматриваемых законодательством правовых конструкций, а также за счет разработки продуманных решений для каждой категории потенциальных клиентов.

Наряду с существованием специальных ипотечных банков, находящихся под жестким государственным надзором, и надежной сети профессиональных кадастровых служб одним 
из факторов обеспечения надежности системы ипотечного кредитования является оптимизация условий предоставления ипотечных кредитов для лиц, накопивших средства для оплаты значительной части (около 40-50\%) стоимости приобретаемого жилья.

Для накопления данной суммы заинтересованное лицо может воспользоваться как обычными банковскими услугами и инвестиционными инструментами, так и возможностями открытия специального накопительного счета для внесения средств, предназначенных для оплаты части приобретаемой в дальнейшем жилой недвижимости. Лица, накопившие необходимую сумму на таком счете, приобретают права на получение льготного кредита и дотаций от государства.

Реализация данной модели осуществляется через систему действующих в Германии ссудосберегательных касс, представляющих собой специализированные кредитные организации, совмещающие функции сберегательного банка как депозитария, ведущего накопительные счета, и функции института ипотечного кредитования, предоставляющего целевые ипотечные кредиты лицам, ранее осуществившим накопление первичного взноса на приобретение жилой недвижимости.

Вкладчики таких ссудо-сберегательных касс принимают на себя обязательства в течение определяемого договором срока вносить определяемые договором платежи на открытые для них накопительные счета. Проценты, начисляемые на такие целевые депозиты, ниже рыночных, что компенсируется возможностью получения добросовестным вкладчиком в дальнейшем кредитных средств под процент, который также будет значительно ниже среднего рыночного процента на рынке ипотечного кредитования.

При такой модели вкладчик опосредованно кредитует приобретение жилья другими лицами, позволяя им получать ипотечные кредиты под низкие процентные ставки, чтобы по окончании накопительного периода также воспользоваться возможностью получения ипотеки по льготной ставке.

Значительным преимуществом данной модели является то, что благодаря ей становится возможным абсолютный контроль за добросовестностью участников на обеих этапах реализации договорных отношений: при накоплении первой части платежа за приобретаемую недви- жимость и при осуществлении выплат по предоставленному ипотечному кредиту.

Если вкладчик не обеспечит своевременное и регулярное пополнение своего накопительного счета, он лишится возможности получения ипотечного кредита. Если он не будет своевременно осуществлять платежи в счет погашения предоставленного кредита, то причиняемые в результаты убытки будут в любом случае возмещены за счет приобретенной недвижимости, то есть фактически за счет части средств, ранее отложенных вкладчиком.

Кроме того, регулярно пополняя накопительный счет в течение достаточно продолжительного периода вкладчик доказывает свою платежеспособность, дисциплинированность и надежность в качестве стороны заключенного им договора.

В свою очередь государство, поддерживая и поощряя подобные ссудо-сберегательные отношения, предоставляя различного рода льготы участникам системы также имеет важные гарантии того, что поддержка и льготы будут представляться добросовестным лицам, действительно заинтересованным в улучшении жилищных условий.

Интересен опыт совмещения поддержки накопительной системы ипотечного страхования и стимулирования рождаемости в молодых семьях. Так, государство, поддерживая приобретение молодыми семьями жилья на условиях ссудо-сберегательной системы, при наличии в таких семьях не менее двух детей предоставляет им различного рода субсидии, существенным образом облегчающие и ускоряющие погашение кредита, полученного на приобретение жилья [8, С. 279-280]. Таким образом, средства, направляемые на поддержку рождаемости, целевым образом попадают в семьи наиболее добросовестных налогоплательщиков, способных обеспечивать как экономический, так и демографический рост, и при этом еще способствуют росту обеспеченности жильем семей с двумя и более детьми.

Данная система создает все условия для почти полного исключения спекулятивных или мошеннических действий, так как лежащие в ее основе принципы не позволяют воспользоваться ипотечным кредитом или связанными с ним льготами случайным лицам, не доказавшим свою добросовестность и состоятельность, не подтвердивших регулярность своих доходов, в частности, на этапе накопления первичного 
взноса за приобретаемое жилое помещение.

Разумеется, важнейшую роль в функционировании данной системы играет государство, жесткий контроль со стороны которого исключает возможность направления находящихся на накопительных счетах средств на какие-либо цели, отличные от приобретения недвижимого имущества, либо их предоставление на условиях, отличных от описанных выше. Государство также обеспечивает надзор за правильностью методик оценки приобретаемой и передаваемой в залог недвижимости и иными действиями и решениями, которые могли бы создать угрозу для стабильности ссудо-сберегательных учреждений.

Указанные факторы значительно повышают надежность рассмотренного варианта ипотечного кредитования, что позволяет с учетом низких рисков и высокой гарантированности сделанных вложений предоставлять участникам системы ипотечные кредиты под низкие ставки: «Это замкнутая модель организации ипотечного финансового рынка, которая создана и работает по сберегательно-ссудному принципу для обеспечения дешевыми долгосрочными ресурсами жилищного ипотечного кредитования» [3, С. 48].

Ссудо-сберегательная модель финансирования приобретения жилой недвижимости является одной из основных систем ипотечного кредитования в современной Германии. В данной системе участвует почти четверть населения страны [1, С. 135], благодаря чему она играет важнейшую роль в обеспечении доступности жилья для граждан страны, сдерживании спекулятивных колебаний и значительного роста процентных ставок по ипотечным кредитам, выдаваемым банками и иными кредитными учреждениями.

Так, важнейшим преимуществом ссудосберегательной модели считается ее малая зависимость от состояния финансового рынка и колебаний связанных с ним процентных ставок, поскольку при такой модели «банку нет необходимости привлекать кредитные ресурсы из внешних источников: ему следует определить только эффективный размер процентной маржи» [4, С. 81], то есть разницы между процентными ставками, под которые он привлекает средства, и процентными ставками, под которые он предоставляет такие средства вкладчикам, переходящим в категорию получателей ипотечного кредита.

Заимствование приведенного опыта и реализация данной модели ипотечного кредитования в Российской Федерации могли бы создать условия для роста стабильности гражданскоправового оборота, предоставления важных гарантий сохранности средств граждан, накапливаемых ими в целях приобретения недвижимого имущества, в том числе в целях улучшения своих жилищных условий, снижения рисков для всех участников отношений в сфере ипотечного кредитования, оптимизации ставок ипотечных кредитов.

Вследствие этого ипотека могла бы стать доступной для более широкого круга российских граждан при снижении ипотечной нагрузки на бюджеты российских семей, использующих различные варианты ипотечного кредитования для улучшения своих жилищных условий.

\section{Библиографический список}

1. Александрова А.Ю. Совершенствование правового регулирования ипотечного кредитования в Российской Федерации.-М., 2005.- 135 с.

2. Афанасьева О.Н. Особенности развития ипотечного кредитования за рубежом // Евразийский союз ученых. 2016. № 29.- С. 20-23.

3. Иванова А.А. Сравнительный анализ ипотечного жилищного кредитования в США, Франции, Германии и России // Информационные технологии в машиностроении, образовании и экономике. 2018, № 1-2.C. $45-52$.

4. Литвинова С.А. Применение накопительной ипотеки в России // Экономика и управление. 2013. № 5.C. 80-83.

5. Понька В.Ф. Залог недвижимого имущества: риски для кредитора // Экономические науки. 2016. № 136.C. 72-73.

6. Понька В.Ф. О концепции развития ипотечного жилищного кредитования в Российской Федерации // Вестник экономической интеграции. 2010. № 2.- С. 38-40.

7. Понька В.Ф. Особенности законной и договорной ипотеки в действующем гражданском праве // Вопросы экономики и права. 2018. № 4.- С. 30-31. 
8. Сироткин В.А. Накопительная система с участием государства как форма повышения доступности приобретения жилья // Экономика региона. 2012. № 3.- С. 278-284. 